\title{
Bionomia de Monoeca xanthopyga Harter-Marques, Cunha \& Moure (Hymenoptera, Apidae, Tapinotaspidini) no Planalto das Araucárias, Rio Grande do Sul, Brasil
}

\author{
Rodrigo da Cunha ${ }^{1,2} \&$ Betina Blochtein ${ }^{1}$
}

${ }^{1}$ Faculdade de Biociências, Pontifícia Universidade Católica do Rio Grande do Sul. Avenida Ipiranga, 6681, 90619-900 Porto Alegre, Rio Grande do Sul, Brasil. E-mail: sombranssa@hotmail.com

2 Bolsista do CNPq.

\begin{abstract}
Life history of Monoeca xanthopyga Harter-Marques, Cunha \& Moure (Hymenoptera, Apidae, Tapinotaspidini) at the Araucária Plateau, Rio Grande do Sul, Brazil. A study of the life history of the solitary bee Monoeca xanthopyga, was conducted at the Araucária Plateau, at the state of Rio Grande do Sul. The study focused the seasonality, sexual behavior, females activity during nest building, the exploited plant resources and the associated parasitoids. Three nest aggregations of $M$. xanthopyga built in clay soil with few plant cover or none at all, were studied on the Parque Nacional dos Aparados da Serra, located in Cambará do Sul, Rio Grande do Sul State. The nests were randomly distributed in areas up to eight square meters in size and reach a maximum density of 57 nests per square meter. The only one generation occurred from January to April. The immature stayed in diapausa in the prepupa stage during eight to 11 months. Males emerged a few days before females, and disappeared from the aggregations four days before the end of females activities. The search for females to mate occurred at nests from the previous year, where many males struggled for a single emergent female. It is suggested that males perceive smells emitted by females. Copulation's lasted, on average, 26 seconds and, immediately after it, the couple separated. Nest building females were not attractive to males. Mating tests, at artificial environments showed the occurrence of copulation with both virgin and fertilized females. After mating, the females returned to the aggregations and established new nests by digging new tunnels, or by using abandoned nests. The bee's flying activities began around 6 A.M. and lasted up to 6 P.M. The females did, on average, eight trips per day, each one lasting 31,4 minutes. They returned from the trips carrying pollen and/or floral oils. These resources were obtained from flowers of Malpighiaceae and Fabaceae species. Pollinaria from orchids of the genus Oncidium Sw. were carried accidentally by males and females. Mutilid parasitoids were present at the aggregations of $M$. xanthopyga during all the period of the activities. One species of Traumatomutilla André, 1903 was related to the immature of these bees, composing the first registration of inhabitant of this Mutillidae.
\end{abstract}

KEY WORDS. Floral rewards, Monoeca xanthopyga, nest aggregations, parasitoids, reproductive behavior, seasonality, Tapinotaspidini.

Roubiк (1989) relatou que o número de espécies de abelhas conhecidas em todo o mundo aproximava-se de 20.000 e sugeriu, baseado na proporção de novas descobertas, que o grupo seja composto de, pelo menos, o dobro deste número. Na América do Sul, os registros são superiores a 7.000 espécies, sendo 4.000 destas encontradas no Brasil (O'Toole \& Raw 1991). No Rio Grande do Sul, a apifauna está representada por 320 espécies (Wittmann \& Hoffmann 1990). Destas, 292 ocorrem na encosta atlântica e planície costeira do Estado (SANTOS 1999a). Apesar da alta diversidade da apifauna neotropical, estudos sobre abelhas solitárias são restritos (Michenter \& LANGE 1958, Plowright \& Laverty 1984, Rozen 1984, Seeley 1985, Bawa 1994, Hiller \& Wittmann 1994, Schlindwein 1995, Santos 1997, 1999b, WiLms et al. 1997).

Os registros das sete espécies descritas do gênero Monoeca Lepeletier \& Serville, 1828, para o Brasil limitam-se aos estados do Rio de Janeiro, São Paulo, Paraná, Santa Catarina e Rio Grande do Sul (Michener \& Lange 1958, Rozen 1984, WitTManN \& Hoffmann 1990, Harter-Marques et al. 2001, Cunha \& Blochtein 2002). Apenas duas espécies foram mencionadas para o Rio 
Grande do Sul: Monoeca lanei Moure, 1944 e Monoeca xanthopyga Harter-Marques, Cunha \& Moure, 2001.

Abelhas do gênero Monoeca são altamente sazonais. Os adultos das espécies deste gênero foram coletados entre os meses de novembro e abril (Michener \& LANGe 1958, Rozen 1984, WitTmann \& Hoffmann 1990, Santos 1999a, Harter-Marques et al. 2001). O'Toole \& Raw (1991) enfatizam que nos trópicos a maior parte das espécies de abelhas solitárias emerge no final da estação de alta pluviosidade, coincidindo com as floradas responsáveis pela oferta de néctar e pólen. Em regiões subtropicais e temperadas, após o término das atividades de vôo, os imaturos permanecem em diapausa no interior dos ninhos até que as condições climáticas permitam a continuidade de seu desenvolvimento (MANSINGH 1971).

Os adultos recém emergidos desenvolvem estratégias para a localização e/ou atração de pares para acasalamento. Estabelecimento de território, patrulha em flores ou em ninhos são freqüentes em espécies de Apidae (Hurd 1958, Roubik 1989, Alcock et al.1978, ALCOCK 1980, 1991).

As espécies do gênero Monoeca constróem seus ninhos no solo, próximos uns dos outros, formando agregações (RozEN 1984). Sснвоттку (1901) observou Pachycentris schrottkyi Friese, 1902, (= Monoeca piliventris Friese, 1899) nidificando em uma ladeira no Paraná. Ninhos desta espécie, na mesma localidade, foram encontrados por IHERING (1904) em um barranco de $10 \mathrm{~m}$ de altura. Michener \& LANGe (1958) registraram um ninho de uma espécie não determinada de Monoeca em substrato horizontal, entre gramíneas, no Paraná. No mesmo Estado, Rozen (1984) estudou uma agregação de ninhos de M. lanei e descreveu as atividades das fêmeas e a estrutura dos ninhos e das células de cria.

No Planalto das Araucárias do Rio Grande do Sul, o encontro das Florestas Ombrófila Mista (Mata com Araucária) e Densa (Mata Atlântica) suporta fauna e flora amplamente diversificadas, inclusive com casos de endemismos (Estivalet 1995). O inventário de himenópteros realizado por WitTMANN \& HOFFMANN (1990) aborda a situação de conservação das abelhas no Estado e cita espécies cuja distribuição está relacionada ao encontro destas florestas, consideradas seriamente ameaçadas (Wittmann et al. 1988). A avaliação recente da fauna do Rio Grande do Sul indicou 11 espécies de abelhas em distintas categorias de ameaça, inclusive de M. xanthopyga, recentemente descrita, endêmica do Planalto das Araucárias.

Objetivou-se o estudo de M. xanthopyga com ênfase em sua sazonalidade, caracterização das agregações de ninhos, comportamento reprodutivo, atividades das fêmeas durante a construção dos ninhos, recursos florais utilizados e registro de parasitóides associados aos imaturos.

\section{MATERIAL E MÉTODOS}

O levantamento de agregações de ninhos de $M$. xanthopyga foi realizado no Planalto das Araucárias do Rio Grande do Sul, nos municípios de São Francisco de Paula e Cambará do Sul. Viagens mensais à Região foram realizadas durante o período de dezembro de 1998 a abril de 2000 .

O estudo da bionomia de M. xanthopyga foi conduzido no Parque Nacional dos Aparados da Serra (PARNA Aparados da Serra), no município de Cambará do Sul, área de 10.500 ha, com altitude média de $1000 \mathrm{~m}$, onde a Mata Atlântica distribuise pelas encostas até uma altitude de $600 \mathrm{~m}$. Nas bordas do
Planalto encontra-se a matinha nebular e no patamar superior estão presentes as matas com Araucaria angustifolia (Bertol.) O. Ktze e os campos (Estivalet 1995).

O clima da região é definido como subtropical de superúmido a úmido, com regime pluviométrico oscilando entre 1.700 e $2.500 \mathrm{~mm}$ por ano. A temperatura média anual é amena, havendo uma distinção nítida entre as quatro estações, sendo as médias anuais mínimas e máximas, respectivamente, $9,9^{\circ} \mathrm{C}$ e $20,3^{\circ} \mathrm{C}$ (IbGe 1986).

As agregações de ninhos encontradas no PARNA Aparados da Serra foram demarcadas com pedras, estacas de madeira e fitas plásticas e acompanhadas nos períodos de janeiro a abril de 1999 e 2000. As coordenadas geográficas das agregações foram obtidas no sistema UTM, fuso 22, com aparelho GPS (Pioner ${ }^{\circledR}$ modelo Maagellan).

A cobertura vegetal dos sítios das agregações foi descrita a partir dos elementos predominantes e o solo caracterizado quanto sua origem geológica.

À medida em que foram fundados, os ninhos de duas agregações foram marcados individualmente com anéis plásticos e acompanhados semanalmente até o término da construção. Em duas agregações mensurou-se, respectivamente em 1999 e 2000 (agregação A) e em 1999 (agregação B), a área ocupada pelos ninhos, o número total de ninhos construídos, a distância entre suas entradas e o diâmetro das entradas de 73 ninhos.

Seis fêmeas emergentes de ninhos da agregação A, em $12 / \mathrm{I} / 2000$, foram capturadas com o auxílio de rede entomológica e posteriormente marcadas no tórax com tinta colorida atóxica, possibilitando o acompanhamento individualizado de suas atividades. Duas fêmeas que construíam ninhos foram observadas em suas atividades externas por três dias não consecutivos.

Em janeiro e fevereiro de 2000, treze machos presentes na agregação A foram capturados com rede entomológica e marcados individualmente visando-se verificar deslocamentos entre as agregações de ninhos no PARNA Aparados da Serra.

O comportamento de acasalamento dos machos foi descrito. Nos dois anos, o número de machos presentes na agregação $\mathrm{A}$ foi quantificado em intervalos de até cinco dias, através de uma caminhada lenta no entorno da agregação, em três horários: 8:30-9:00 h, 11:30-12:00 h e 15:00-15:30 h.

Dois testes de acasalamento foram realizados em placas de Petri com o objetivo de verificar a atratividade de fêmeas recém emergidas e em período de nidificação e o número de machos aceitos por cada uma. As abelhas (oito fêmeas e 72 machos) foram coletadas e colocadas aos pares em placas de Petri. Após a cópula, identificada por seu comportamento característico de batimento das asas, o macho foi substituído por outro, até o número máximo de dez. O comportamento dos indivíduos e a duração das cópulas foram anotados.

Ao longo da estação, procurou-se observar, em uma área de cerca de $1 \mathrm{Km}$ de raio no entorno da agregação, indivíduos de M. xanthopyga coletando recursos florais em suas fontes alimentares. Além disso, cargas de pólen transportadas por doze fêmeas e pólen depositado em dez células de cria foram amostrados. As preparações polínicas seguiram o método proposto por Salgado-Labouriau (1973) e as análises qualitativas, visando-se a identificação das plantas visitadas, foram realizadas através de consulta à palinoteca do Laboratório de Pesquisas Biológicas, Pontifícia Universidade Católica do Rio grande do Sul (PUCRS). 
Políneas transportadas na cabeça de machos e fêmeas presentes nas agregações foram coletadas, conservadas em álcool 70\% e identificadas até o nível genérico.

Os insetos emergentes de 15 ninhos de M. xanthopyga, construídos em 1999, foram coligidos a partir do uso de cinco armadilhas dispostas sobre suas entradas durante o período de 15/I a 10/III/2000 e inspecionadas diariamente. Cada armadilha constituía-se de uma meia esfera de $40 \mathrm{~cm}$ de diâmetro e $30 \mathrm{~cm}$ de altura, confeccionada com armação metálica e coberta com tecido.

Os insetos coletados foram depositados na coleção do Museu de Ciências e Tecnologia, PUCRS.

Escavações de ninhos de $M$. xanthopyga foram procedidas bimensalmente de abril de 1999 a março 2000 a fim de acompanhar o desenvolvimento dos imaturos. As medidas de temperatura foram obtidas com termômetro digital manual.

\section{RESULTADOS E DISCUSSÃO}

Foram encontradas, no Planalto das Araucárias, sete agregações de ninhos de M. xanthopyga (Tab. I). Entretanto, nenhum indivíduo foi observado em flores. Observações de $M$. xanthopyga anteriores a esse estudo também ocorreram junto aos ninhos. O único registro, no Rio Grande do Sul, de indivíduos do gênero em flores é de Santos (1999a), que observou fêmeas coletando pólen na Bignoniaceae Cuspidaria pterocarpa (Cham.) D.C.

Tabela I. Localização das agregações de ninhos de $M$. xanthopyga, encontradas no período de 1998 a 2000, no Rio Grande do Sul.

\begin{tabular}{|c|c|c|}
\hline Agregação & Município/localidade & Coordenadas geográficas \\
\hline A & $\begin{array}{l}\text { Cambará do Sul/PARNA Aparados } \\
\text { da Serra }\end{array}$ & 6.773.884 mN $588.427 \mathrm{mE}$ \\
\hline B & $\begin{array}{l}\text { Cambará do Sul/PARNA Aparados } \\
\text { da Serra }\end{array}$ & $6.773 .884 \mathrm{mN} 588.432 \mathrm{mE}$ \\
\hline $\mathrm{C}$ & $\begin{array}{l}\text { Cambará do Sul/PARNA Aparados } \\
\text { da Serra }\end{array}$ & $6.778 .913 \mathrm{mN} 589.312 \mathrm{mE}$ \\
\hline $\mathrm{D}$ & Cambará do Sul/Fazenda Fogaça & $6.788 .956 \mathrm{mN} 583.997 \mathrm{mE}$ \\
\hline $\mathrm{E}$ & $\begin{array}{l}\text { São Francisco de Paula/Parque das } \\
\text { Cachoeiras }\end{array}$ & $6.741 .760 \mathrm{mN} 542462 \mathrm{mE}$ \\
\hline $\mathrm{F}$ & $\begin{array}{l}\text { São Francisco de Paula/Estrada para } \\
\text { Maquiné }\end{array}$ & $6.748 .517 \mathrm{mN} 560.180 \mathrm{mE}$ \\
\hline G & $\begin{array}{l}\text { São Francisco de Paula/FLONA- } \\
\text { IBAMA }\end{array}$ & 6.738.449 mN $580.052 \mathrm{mE}$ \\
\hline
\end{tabular}

\section{Agregações de ninhos}

As fêmeas de $M$. xanthopyga construíram seus ninhos no solo, em superfícies planas ou em barrancos, sempre à beira de estradas ou trilhas (Fig. 1). A entrada de cada ninho media 9 $m m$ de diâmetro $(n=73)$ e era circundada por uma elevação de terra solta, resultante da remoção do substrato pela fundadora.

Os locais onde foram encontradas agregações de ninhos de $M$. xanthopyga apresentaram cobertura vegetal variável: ausente ou esparsa, marcada pela presença de musgos e vegetação herbácea, com predomínio de compostas e gramíneas. O substrato utilizado mostrou-se argiloso e compacto, caracterizado geologicamente como rocha alterada in sito (elúvio), com deposição de material transportado.

A preferência de certas espécies de abelhas solitárias por solos argilosos foi destacada por Linsley (1958). Da mesma maneira, Rozen (1984) notou que agregações de ninhos de $M$. lanei encontravam-se em solo constituído de material argiloso, seco na superfície e úmido na camada inferior. Além das características do substrato, LINSLEY (1958) considera fundamental a proximidade de fontes de pólen, néctar e de água para o estabelecimento de ninhos. Apesar das agregações de $M$. xanthopyga observadas localizarem-se próximas a recursos hídricos, as fontes alimentares não foram encontradas em um raio de $1 \mathrm{Km}$ no entorno dos ninhos.

Michener et al. (1958), estudando a distribuição de agregações de ninhos em barrancos sugerem que a exposição solar, a constituição do solo e outros fatores ambientais são importantes para o estabelecimento dos ninhos. A formação de agregações, em muitos casos, independe da disponibilidade de grandes áreas para a nidificação.

Michener (1974) presume que agregações resultam da tendência de as abelhas retornarem aos locais de emergência. As abelhas são hábeis para reconhecer e retornar aos locais de emergência, através da marcação de pontos de referência e através da percepção de sinais químicos. Segundo Michener \& LANGE (1958), outras espécies de Apinae (anteriormente Anthophorinae) como Ancyloscelis Latreille, 1829, Paratetrapedia Moure, 1941, Exomalopsis Spinola, 1853 e Tapinotaspis Holmberg, 1903, também constróem ninhos no solo formando agregações semelhantes às de Monoeca. Michener (2000) relata que as espécies mais conhecidas do grupo nidificam em agregações no solo.

As agregações de $M$. xanthopyga estudadas diferiram entre si quanto a extensão da área ocupada e a quantidade de ninhos agrupados. O monitoramento dos ninhos de duas agregações localizadas no PARNA Aparados da Serra, ao longo do período de atividades de vôo das abelhas, revelou que a maior densidade de ninhos ocorreu na agregação de menor área de abrangência (Tab. II).

Tabela II. Distribuição dos ninhos de Monoeca xanthopyga em duas agregações localizadas no PARNA Aparados da Serra.

\begin{tabular}{ccccc}
\hline Agregação & Ano & $\begin{array}{c}\text { Número de } \\
\text { ninhos }\end{array}$ & $\begin{array}{c}\text { Área total da } \\
\text { agregação }\left(\mathrm{m}^{2}\right)\end{array}$ & $\begin{array}{c}\text { Densidade média } \\
\text { dos ninhos } / \mathrm{m}^{2}\end{array}$ \\
\hline A & 1999 & 168 & 8,40 & 20,0 \\
A & 2000 & 131 & 8,40 & 15,6 \\
B & 1999 & 89 & 1,55 & 57,0 \\
\hline
\end{tabular}

A distribuição dos ninhos da agregação A (07/II/1999) apresentou-se irregular, com a distância entre as entradas dos ninhos adjacentes variando de 3,0 a 97,2 cm.

Segundo EicKwort et al. (1977), em abelhas do gênero Diadasia Patton, 1879, (Emphorini), estudadas no Arizona, a área ocupada pela agregação foi de $3 \mathrm{~m}^{2}$ e a distância média entre os ninhos foi de $22,2 \mathrm{~cm}$. Para o gênero Paratetrapedia (Tapinotaspidini) foram localizadas agregações construídas no 

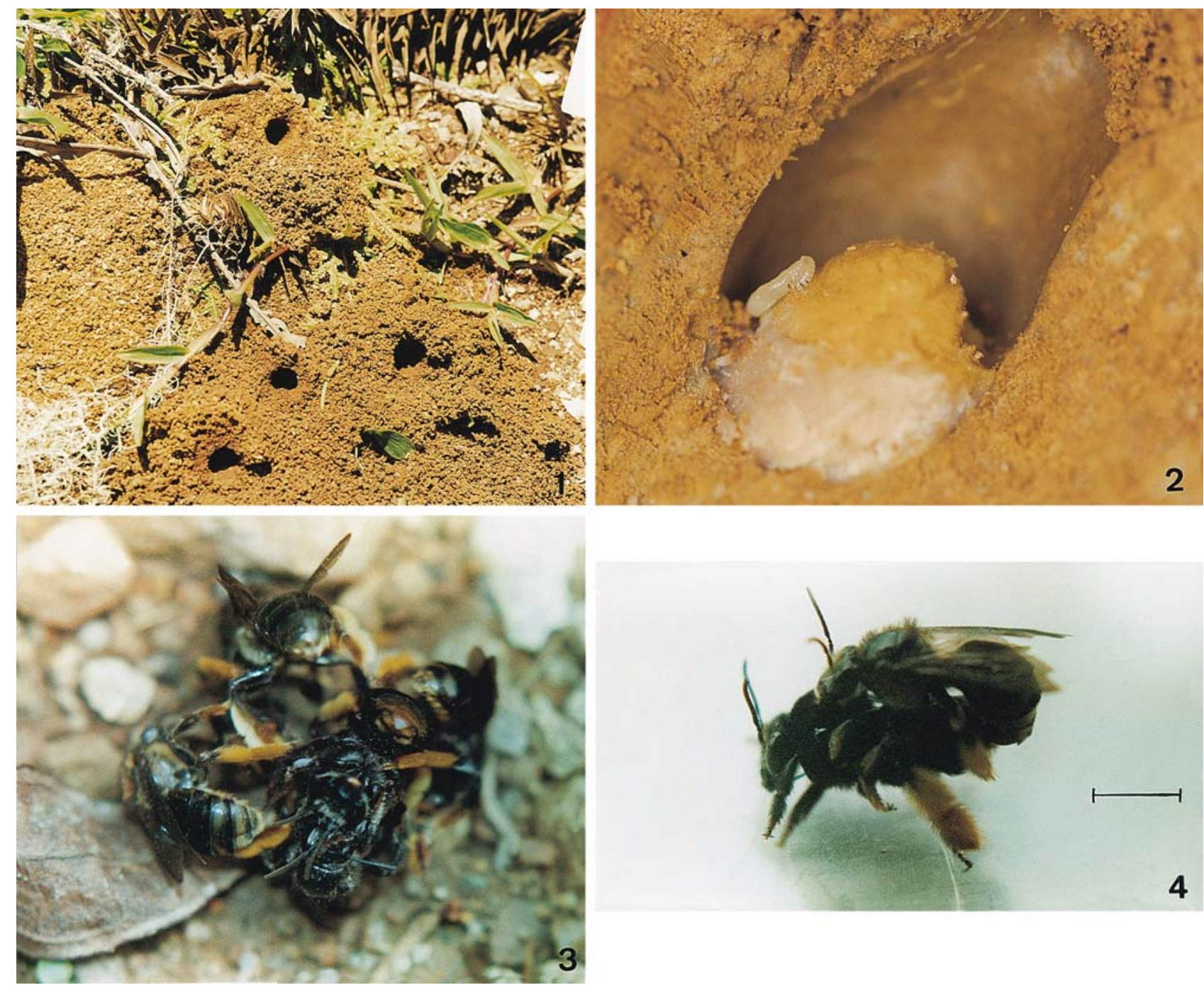

Figuras 1-4. (1) Entradas de ninhos de M. xanthopyga mostrando as características torres de terra solta; (2) corte em célula com larva de M. xanthopyga alimentando-se de pólen; (3) machos de $M$. xanthopyga disputando uma melhor posição na entrada de um ninho onde ocorria a emergência de uma fêmea e; (4) macho e fêmea em acasalamento. Escala: 5,2 mm.

solo, de até $10 \mathrm{~m}^{2}$, densamente ocupadas com ninhos. Situação semelhante foi verificada para espécies do gênero Melitoma Lepeletier \& Serville, 1828 da mesma tribo, que constróem seus ninhos em bancos verticais ou horizontais (Michener \& LANGE 1958).

\section{Sazonalidade}

Monoeca xanthopyga é univoltina. Nas agregações estudadas os imaturos permaneceram no interior dos ninhos durante o período de abril a janeiro. Após, as larvas (Fig. 2) consumiram as provisões depositadas pelas genitoras e assumiram a forma de pré-pupa, permanecendo em diapausa por oito a 11 meses. As primeiras pupas foram constatadas no final de dezembro e a presença de abelhas junto aos ninhos foi registrada durante o período de 11 a 12 semanas. Em 1999, os primeiros machos foram registrados no dia 18 de janeiro e os últimos em 21 de fevereiro. No ano de 2000, o período de atividades dos machos foi de 12 de janeiro a 29 de fevereiro (Fig. 5). O início das atividades das fêmeas foi constatado respectivamente, em 1999 e 2000, quatro e 11 dias após a observação dos primeiros machos, estendendo-se até a primeira semana de abril.

Os registros de espécies do gênero Monoeca feitos por 
Michener \& Lange (1958), Rozen (1984) e Wittmann \& Hoffmann (1990) coincidem com os meses mais quentes do ano, assim como foi constatado em dois anos consecutivos para $M$. xanthopyga.

A partir das armadilhas dispostas sobre 15 ninhos, construídos em 1999, constatou-se a emergência de 44 fêmeas e 51 machos de $M$. xanthopyga. Portanto, o número de indivíduos emergentes foi de duas a três fêmeas e de três a quatro machos por ninho.

\section{Comportamento reprodutivo}

O número de machos de $M$. xanthopyga nas agregações variou no decorrer da estação de vôo, sendo que a maior freqüência ocorreu no mês de fevereiro (Fig. 5).

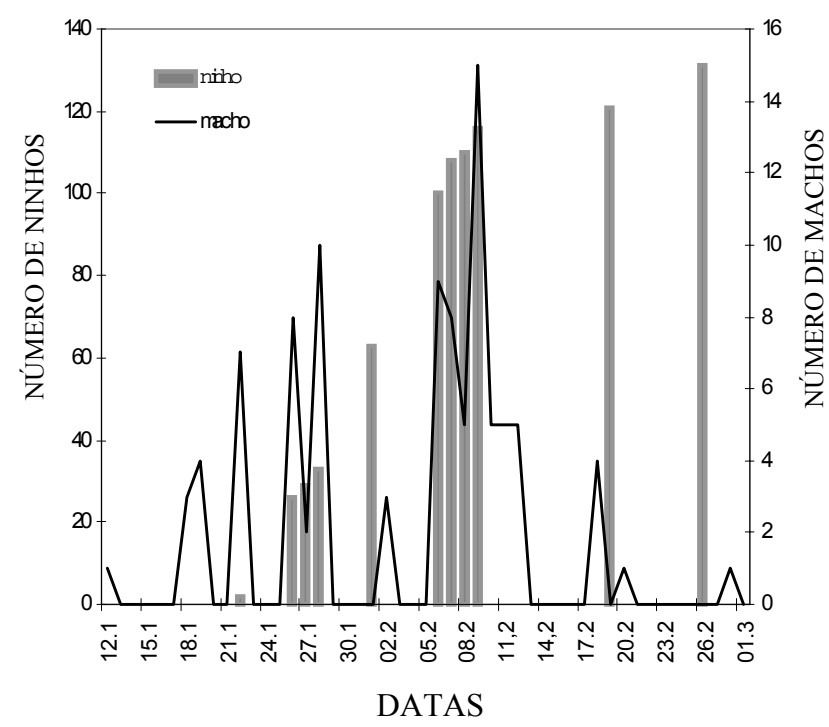

Figura 5. Número médio de machos e número de ninhos em construção na agregação A no ano de 2000.

Desde o início do período de atividades, os machos patrulhavam ativamente as agregações. Durante várias horas do dia desenhavam vôos rasantes e sinuosos sobre as agregações, a poucos centímetros de distância do solo, à procura de fêmeas. Eles interrompiam os vôos para inspecionar os ninhos, as fêmeas presentes nas agregações e eventualmente até mesmo machos de mutilídeos.

Em determinados momentos do dia, vários machos aglomeravam-se na entrada de um ninho específico, onde havia emergência de fêmeas e disputavam a posição da abertura do túnel lutando por vários minutos para deslocar seus rivais (Fig. 3). Assim, quando as fêmeas emergiam, os machos buscavam pares para o acasalamento. Não foram observadas tentativas de cópula com fêmeas que construíam ninhos.

$\mathrm{O}$ aglomerado de machos formava-se antes do aparecimento da fêmea emergente. Por esta razão, sugere-se que a percepção destes indivíduos seja resultante de estímulos olfativos (feromônios) emitidos pelas fêmeas. Este comportamento é conhecido para outras espécies, a exemplo do gênero Lasioglossum Curtis, 1833, onde os machos reagem a sinais químicos emitidos pelas fêmeas (SMITH 1983).

No momento da emergência de uma fêmea, os machos procuraram montar sobre ela. Minutos após, sucedeu-se a cópula (Fig. 4), com duração de cerca de 20 segundos $(n=8)$ e o par separou-se. Logo após a cópula, as fêmeas afastaram-se da agregação provavelmente para se alimentar.

Os machos despendiam várias horas do dia nas agregações. Cinco machos marcados patrulharam (09/II/2000) alternadamente duas agregações que distavam $29 \mathrm{~m}$ uma da outra. Entretanto, os mesmos indivíduos não foram observados na agregação C, localizada a 1.120 m de distância da agregação A.

As atividades de vôo dos machos nas três agregações não foram sincrônicas. Em 1999 o último registro ocorreu nos dias 7, 13 e 21 de fevereiro, respectivamente nas agregações A, B e C.

Os testes com pares de M. xanthopyga, em placas de Petri, mostraram que diferentemente das observações em ambiente natural, fêmeas virgens e fecundadas copularam com os machos. A cópula durou em média 26,4 segundos $(n=20)$. As pernas anteriores do macho posicionavam-se sobre a cabeça da fêmea e as antenas dos dois indivíduos tocavam-se. Durante o movimento de cópula, ao mesmo tempo em que produziam um zumbido característico, as pernas posteriores do macho esfregavam o abdômen da fêmea (Fig. 4).

Fêmeas recém fecundadas retornaram à agregação de origem em busca de um local para nidificar. Foram observadas iniciando seus ninhos sob pedras, em frestas na vegetação ou a partir de uma cavidade preexistente no solo. Após alguns minutos de vôos curtos, interrompidos para inspecionar o substrato, escolheram um local e escavaram até sumirem sob uma torre de terra solta.

A reutilização de ninhos antigos foi constatada pela presença de terra solta proveniente das escavações, onde anteriormente indivíduos haviam emergido e pela observação de fêmeas aprovisionando e defendendo tais ninhos.

Duas fêmeas, acompanhadas em suas atividades externas ao ninho, realizaram em média oito viagens diárias com duração média de 31,4 minutos $(\mathrm{n}=32$ ) (Fig. 6). O maior intervalo de tempo despendido no interior do ninho durante o dia, foi de $1 \mathrm{~h}$ e $22 \mathrm{~min}$. Sugere-se que a fêmea neste período estivesse ovipositando ou construindo células. Durante a noite as fêmeas movimentaram terra para fora dos ninhos, sugerindo a construção de células.

Observações comportamentais demonstraram que as fêmeas iniciaram suas viagens no período matinal, a partir das $9 \mathrm{~h}$ e 20 min. Entretanto, ao longo da estação as abelhas voavam desde as primeiras horas da manhã, próximo das seis horas, quando a temperatura era superior a $15^{\circ} \mathrm{C}$ e estendiam-se até aproximadamente às 18 horas. As atividades foram interrompidas quando as condições climáticas mostraram-se desfavoráveis, com precipitação, neblina ou baixa temperatura. Nestas situações as fêmeas permaneceram no interior de seus ninhos, enquanto os machos abrigaram-se em ninhos antigos.

\section{Recursos Florais}

Nas viagens de coleta as abelhas transportavam pólen e/ou óleos florais identificados pelo aspecto gelatinoso e brilhante. A análise dos grãos de pólen transportados pelas abelhas e armazenado nos ninhos (células) revelou que estas 


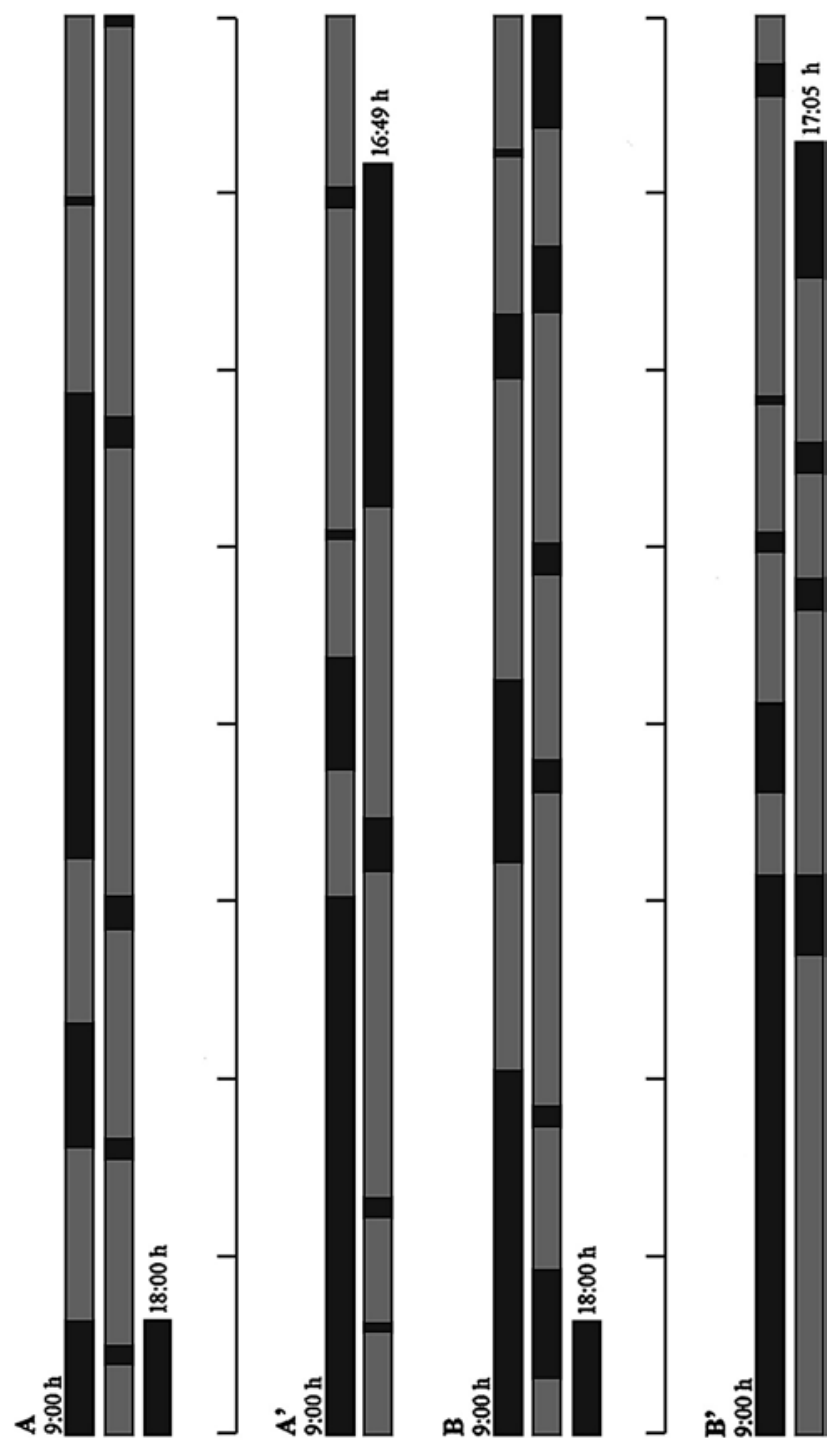

Figura 6. Atividades de vôo de duas fêmeas de Monoeca xanthopyga marcadas individualmente. (A) 08/I/2000, (A') 28/I/2000, (B) 27/ 1/2000, ( $\left.B^{\prime}\right)$ 28/1/2000, (cinza escuro) no interior do ninho, (cinza claro) fora do ninho, (branco) 30 minutos.

são possivelmente especializadas em flores de Malpighiaceae e Fabaceae. Nas células de cria, o pólen das duas famílias vegetais apresentava-se em camadas. O pólen de Malpighiaceae, de coloração branca, encontrava-se na camada inferior e o pólen amarelo, de Fabaceae, na superior. Segundo CunHa \& Blochtein (2002), a composição do suprimento larval de M. xanthopyga foi de $60 \%$ de pólen, $30 \%$ de óleos e $10 \%$ de outros componentes. Buchmann (1987) cita que abelhas do gênero Monoeca são coletoras de óleos florais em Malpighiaceae. O uso de óleos florais para o aprovisionamento de ninhos da abelha solitária Epicharis dejeanii, Lepeletier, 1841, no Rio Grande do
Sul, foi documentado por Hiller \& Wittmann (1994). Relatam que os óleos coletados eram oriundos de duas espécies de Malpighiaceae e apresentavam-se misturados a uma pequena quantidade de pólen.

Políneas de orquídeas do gênero Oncidium Sw. eram transportadas aderidas à cabeça de machos e fêmeas de $M$. xanthopyga. As políneas não foram utilizadas pelas abelhas e permaneceram aderidas ao corpo durante várias viagens. As flores de Oncidium produzem óleos a partir de elaióforos epiteliais ou de tricomas BuchmanN (1987), portanto, sugere-se que as abelhas sejam atraídas para essas flores para a obtenção dos óleos e que as políneas sejam aderidas acidentalmente.

\section{Parasitóides}

Os insetos associados aos ninhos de M. xanthopyga, constatados a partir da emergência em armadilhas, pertencem ao gênero Traumatomutilla André, 1903, (Mutillidae). Dos quinze ninhos acompanhados emergiram três machos e uma fêmea de Traumatomutilla sp.

Considerando que fêmeas desta espécie escavam o solo, sugere-se que este número possa ser superior ao registrado. Além disso, uma pré-pupa de Mutillidae foi encontrada em um casulo de M. xanthopyga.

Mutilídeos do gênero Traumatomutilla foram constatados nas agregações de $M$. xanthopyga durante todo o período de atividades das abelhas. Machos foram observados alimentandose em inflorescências de compostas do gênero Baccharis Less. D.C. Machos de Traumatomutilla voavam nas áreas de agregações de ninhos a poucos centímetros de altura e cortejavam as fêmeas da mesma espécie que encontravam-se sobre o solo. As fêmeas caminhavam entre os ninhos hospedeiros e com frequência desapareciam escavando a terra solta das torres ou no interior dos túneis das abelhas. Fundadoras hospedeiras foram vistas expulsando fêmeas de Traumatomutilla sp. do interior de seus ninhos.

Segundo Krombein (1967), fêmeas de mutilídeos ovipositam em larvas de outros insetos. HANSON \& GAULD (1995) relatam que fêmeas desta família entram nos casulos dos hospedeiros, abrem um pequeno orifício com as mandíbulas e depositam um ovo. Os mesmos autores registraram associações destes parasitóides com larvas ou pré-pupas de abelhas e vespas, especialmente Sphecidae, além de insetos de outras ordens. Relacionam mutilídeos da América Central com abelhas das famílias Halictidae, Apidae (Euglossini), Megachilidae, Andrenidae e Anthophoridae. Os mesmos autores destacam ainda que pouco é conhecido a respeito da especificidade ao hospedeiro. Este estudo documenta o primeiro registro de hospedeiro das espécies de Traumatomutilla.

\section{AGRADECIMENTOS}

Agradecemos ao Prof. Dr. Dieter Wittmann, pelas sugestões e incentivo na realização deste trabalho, ao Sr. José Humberto, guarda do Parque Nacional dos Aparados da Serra, pela acolhida em sua residência. Ao Dr. William Leslie Overal pela identificação dos parasitóides. À Dra. Birgit Harter-Marques pela ajuda na identificação das plantas e abelhas. Ao Dr. Clemens Schlindwein pela identificação dos tipos polínicos, ao Dr. Jorge Alberto Villwock, pela ajuda na identificação do solo e ao Prof. Dr. Regis Alexandre Lahm pela obtenção das coordenadas geográficas. 


\section{REFERÊNCIAS BIBLIOGRÁFICAS}

Alcock, J.; E.M. Barrows \& G. Gordh. 1978. The ecology and evolution of male reproductive behavior in the bees and wasps. Zoological Journal of the Linnean Society, London, 64: 293-326.

Alcock, J. 1980. Natural Selection and the Mating Systems of Solitary Bees. American Scientist, New York, 68: 146-153.

1991. Mate - locating behavior of Xylocopa californica arizonensis Cresson (Hymenoptera: Anthophoridae). Journal of the Kansas Entomological Society , Manhattan, 64: 349356.

BAWA, K.S. 1994. Pollinators of tropical dioecious angiosperms: a reassessment? No, not yet. American Journal of Botany, New York, 72: 456-460.

BuCHMANN, S.I. 1987. The ecology of oil flowers and their bees. Annual review of Ecology \& Systematics, Palo Alto, 18: 343-369.

Cunha, R. \& B. Blochtein. 2002. Estrutura de ninhos de Monoeca xanthopyga (Hymenoptera, Apoidea, Tapinotaspidini) no Planalto das Araucárias, Rio Grande do Sul, Brasil. Biociências, Porto Alegre, 10: 25-33.

EICKWORT, G.C.; K.R. EICKWORT \& E.G. LinsLey. 1977. Observations on Nest Agregations of the Bees Diadasia olivacea and D. diminuta (Hymenoptera: Anthophoridae). Journal of the Kansas Entomological Society, Manhattan,50: 1-17.

Estivalet, C. 1995. Patrimônio Natural, Região das Hortências. Canela, Associação Ecológica Canela - Planalto das Araucárias. Metroplan, 17p.

Hanson, P.E. \& I.D. Gauld. 1995. The Hymenoptera of Costa Rica. Oxford, Oxford University Press, 893p.

Harter-Marques, B.; R. Cunha \& J.S. Moure. 2001. Uma nova espécie de Monoeca (Hymenoptera, Apidae, Tapinotaspidini) do Planalto das Araucárias, no Rio Grande do Sul, Brasil. Biociências, Porto Alegre, 9 (1): 99-110.

Hiller, B. \& D. WitTmann. 1994. Seasonality, nesting biology and mating behavior of the oil-collecting bee Epicharis dejeanii (Anthophoridae, Centridini). Biociências, Porto Alegre, 2 (1): 107-124.

HuRD, P.D. 1958. Observations on the nesting habits of some new world carpenter bees with remarks on their importance in the problem of species formation. Annals of the Entomological Society of America, College Park, 51: 365-375.

Ibge. 1986. Levantamento de Recursos Naturais. Rio de Janeiro, vol. 33, 796p.

IHERING, R.V. 1904. Biologia das abelhas solitárias do Brazil. Versículos do Museu Paulista, São Paulo, 6: 461-481.

Krombein, K.V. 1967. Trap-nesting wasps and bees: life histories, nests, and associates. Washington, D.C., Smithsonian Press, 570p.

Linsley, E.G. 1958. The Ecology of Solitary Bees. Hilgardia, Oakland, 27 (19): 543-591.

Mansingh, A. 1971. Physiological classification of dormancies in insects. The Canadian Entomologist, Ottawa, 121: 745756.

MichenER, C.D. 1974. The social behavior of the bees: a comparative study. Harvard, Harvard University Press, 404p.
. 2000. The Bees of the World. Baltimore and London, The Johns Hopkins University Press, 913p.

Michener, C.D. \& R.B. Lange. 1958. Observations on the ethology of neotropical Anthophorine bees (Hymenoptera: Apoidea). The University of Kansas Science Bulletin, Lawrence, 39: 69-96.

Michener, C.D.; R.B. Lange.; J.J. Bigarella \& R. Salamuni. 1958. Factors influencing the distribution of bees in earth banks. Ecology, Arizona, 39 (2): 207-217.

O' Toole, C. \& A. Raw. 1991. Bees of the world. London, Blandford Publishing, 191p.

Plowright, R.C. \& T.M. Laverty. 1984. The ecology and sociobiology of bumble bees. Annual Review of Entomology, Stanford, 29: 175-199.

Rozen J.G. 1984. Comparative Nesting Biology of the Bee Tribe Exomalopsini. American Museum Novitates, New York, 2798: 1-37.

RoubIK, D.W. 1989. Ecology and natural history of tropical bees. Cambridge, England, Cambridge University Press, $514 \mathrm{p}$.

SALGADO-LABOURIAU, M.L. 1973. Contribuição à palinologia dos cerrados. Rio de Janeiro, Academia Brasileira de Ciências, 291p.

Santos, I.A. 1997. Melittophilous Plants, their pollen and flower visiting bees in southern Brazil: 3. Pontederiaceae. Biociências, Porto Alegre, 5 (1): 3-18.

- 1999a. Abelhas e plantas melíferas da mata atlântica, restinga e dunas do litoral norte do estado do Rio Grande do Sul, Brasil. Revista Brasileira de Entomologia., São Paulo, 43 (3/4): 191-223.

1999b. Distribuição vertical de uma comunidade de abelhas (Hymenoptera, Apoidea) do Rio Grande do Sul. Revista Brasileira de Entomologia, São Paulo, 43 (3/4): 225-228.

Schlindwein, C. 1995. Melittophilus plants, their pollen and flower visiting bees in Southern Brazil. 2. Cactaceae. Biociências, Porto Alegre, 3 (2): 35-71.

Sснвоттку, C. 1901. Biologische Notizen solitärer Bienen von S. Paulo (Brasilien). Allgemeine Zeitschrift Für Entomologie, Berlin, 6: 209-216.

Seeley, T.D. 1985. Honey bee ecology. Princeton, Princeton University Press, 201p.

Sмiтн, B.H. 1983. Recognition of female kin by male bees through olfactory signals. Proceedings of the national Academy of Sciences, Washington, D.C., 80: 4551-4553.

Wilms, W.; L. Wendel; A. Zillikens; B. Blochtein \& W. Engels. 1997. Bees and other insects recorded on flowering trees in a subtropical Araucaria forest in Southern Brazil. Studies on Neotropical Fauna and Environment, Lisse, 32: 220-226.

WitTmann, D.; M. Hoffmann \& E. Scholz. 1988. Southern distributional limits of euglossine bees in Brazil linked to habitats of the Atlantic and subtropical rain forest (Hymenoptera: Apidae: Euglossini). Entomologia generalis, Stuttgart, 14: 53-60.

Wittmann, D. \& M. Hoffmann. 1990. Bees of Rio Grande do Sul, southern Brazil (Insecta, Hymenoptera, Apoidea). Iheringia, Série Zoológica, Porto Alegre, (70): 17-43.

Recebido em 12.VII.2002; aceito em 06.III.2003. 